\title{
Ensino de didática em enfermagem mediado pelo computador: avaliação discente
}

\author{
ENSEÑANZA DE LA DIDACTICA EN ENFERMERIA POR INTERMEDIO DE LA COMPUTADORA: \\ EVALUACIÓN DEL ALUMNADO
}

\author{
Heloisa Helena Ciqueto Peres ${ }^{1}$, Karina Cardoso Meira², Maria Madalena Januário Leite ${ }^{3}$
}

\section{RESUMO}

Este estudo de natureza exploratória descritiva teve como finalidade descrever a opinião dos discentes quanto à forma e conteúdo de um site educacional e a aplicação deste como recurso instrucional no ensino da Disciplina de Didática em Enfermagem de um Curso de Graduação em Enfermagem de uma escola do município de São Paulo. Os sujeitos do estudo foram alunos matriculados nessa disciplina no primeiro semestre do ano letivo de 2003. Os resultados do estudo demonstraram que os discentes apresentam prontidão ao uso da informática e são favoráveis à adoção de novas metodologias de ensino mediadas pelo computador na enfermagem, na perspectiva de ampliar e diversificar as formas de comunicação entre professores e alunos.

\begin{abstract}
This exploratory descriptive study's purpose is to describe what students think regarding the form and content of an educational site and its application as an instructional resource for the discipline of Didactics in Nursing in the undergraduate course in Nursing at a school in the city of São Paulo. The study's subjects were students enrolled in that discipline during the first semester of the school year of 2003. The results show promptness regarding the use of computers on the part of the students, who are favorable to the adoption of new computer-mediated teaching methodologies in Nursing as a means to increase and diversify the forms of communication between instructors and students.
\end{abstract}

\section{KEY WORDS}

Education, nursing.

Educational technology.

Medical informatics.

\section{RESUMEN}

Este estudio de naturaleza exploratoria descriptiva tuvo la finalidad de evaluar un sitio de internet educativo utilizado en la enseñanza de la Disciplina de Didáctica en Enfermería de un Curso de Graduación en Enfermería de una Escuela del Municipio de Sao Paulo, según la opinión de los alumnos. Los sujetos del estudio fueron alumnos matriculados en esa disciplina correspondientes al primer semestre del año escolar del 2003. Los resultados de la investigación demuestran que los alumnos presentan agilidad en el área de informática durante la enseñanza de didáctica y son favorables a la adopción de nuevas metodologías de enseñanza intermediadas por la computadora en enfermería, en la perspectiva de ampliar y diversificar las formas de comunicación entre profesores y alumnos.

\footnotetext{
1 Professora Doutora do Departamento de Orientação Profissional da Escola de Enfermagem da Universidade de São Paulo-EEUSP. hhcperes@usp.br

2 Graduanda do Curso de Graduação da EEUSP e bolsista do Programa Institucional de Bolsa de Iniciação Científica do Conselho Nacional de Desenvolvimento Científico e

Tecnológico-PIBICCNP cardosomeira@ yahoo.com.br 3 Professora Associada do Departamento de Orientação profissional da EEUSP.
}

\section{DESCRITORES}

Educação em enfermagem. Tecnologia educacional. Informática médica.

\section{DESCRIPTORES}

Educación en enfermería. Tecnología educacional. Informática médica. 


\section{INTRODUÇÃO}

No momento atual com a implantação da Lei de Diretrizes e Bases da Educação (LDB) ${ }^{(1)}$, inicia-se a discussão sobre novas propostas curriculares para a enfermagem.

Os autores contemporâneos em educação ${ }^{(2-4)}$ apontam, como maior desafio do processo educacional, a transformação da concepção sobre interação professor-aluno. Essa concepção está fundamentada na visão do professor sobre homem, educação e mundo.

Esse panorama provoca perplexidade na área de educação que tem tido o professor como centro do processo educacional e o espaço da sala de aula como o local onde se dá o ensino. Desafia os educadores a conhecerem, a analisarem e a transformarem, estas novas tecnologias, num instrumento educacional articulado às condições políticas, econômicas, sociais e culturais nas quais o ensino se insere.

Há com a informática novas possibilidades de criação coletiva, de aprendizagem cooperativa e de colaboração em rede, o que tem propiciado o questionamento do processo de trabalho nas instituições, tanto empresas quanto escolas ${ }^{(5)}$.

Nessa nova sociedade que, continuamente, produz conhecimento, a escola que foi constituída quando o saber era um estoque, fundamentado na transmissão do saber e na memorização, deve ser transformada. Assim, pode-se afirmar que a escola deixou de ser o "lócus" privilegiado da educação em nossa sociedade, que está sendo ocupado pelos meios de comunicação em massa, pelas empresas, pelas tecnologias da informação. Por isso atualmente questiona-se o espaço escolar como o único possível para a difusão cultural e a incorporação do conhecimento social produzido ${ }^{(6-7)}$.

O ensino mediado pelo computador utiliza-se da Internet para armazenar, recuperar, e organizar informações, bem como, acompanhar o progresso e os trabalhos dos alunos, possibilitando maior flexibilidade, criatividade, dinamicidade, interação e comunicação no processo educacional ${ }^{(8)}$.

Essas tecnologias vêm impulsionando a implementação da educação à distância, como maneira de promover a educação continuada dos profissionais da área da saúde, frente ao acelerado desenvolvimento tecnológico e a velocidade com que este se torna obsoleto ${ }^{(9)}$.

Nessa proposta, os alunos são protagonistas da aprendizagem buscando construir o seu próprio conhecimento e os professores são os mediadores desse processo, apoiando, ajudando, desafiando, provocando e incentivando a construção do saber. Enfim, orientando o aluno a pensar por si só, a aprender, a se tornar um aprendiz autônomo, pois o saber não pode ser considerado algo a ser memorizado, incorporado, herdado ou transmitido, mas algo que deve ser conjuntamente construído ${ }^{(5)}$.

Assim o sistema educacional convencional terá que se modificar significativamente com as novas tecnologias. Um estudo ${ }^{(5)}$ interroga: "Como manter as práticas pedagógicas tradicionais diante de um conhecimento em contínua transformação e densamente divulgado na sociedade?" A resposta segundo este estudo, não é a utilização a qualquer custo da tecnologia, mas sim o acompanhamento consciente dessa mudança na sociedade que está questionando a organização das instituições, a cultura dos sistemas educativos tradicionais e, principalmente os papéis de professor e aluno.

Na enfermagem, a informática vem sendo alvo de muitas indagações e pesquisas nacionais e internacionais que procuram identificar e descrever as habilidades relacionadas ao uso do computador pelo enfermeiro, definir qual o conteúdo a ser ministrado, bem como, avaliar as disciplinas de informática em enfermagem. Sendo que o propósito fundamental desta área refere-se ao uso das tecnologias da informática em enfermagem ${ }^{(10-17)}$.

Portanto, diante do exposto, teve-se como propósito deste estudo, avaliar, segundo a perspectiva dos discentes, a contribuição que a informática aplicada ao ensino, pode trazer para a Disciplina de Didática em Enfermagem, de um Curso de Graduação em Enfermagem de uma Escola de Enfermagem do Município de São Paulo.

Na disciplina Didática em Enfermagem constam conteúdos que dizem respeito ao processo educacional em saúde, onde são apresentadas as temáticas relativas ao planejamento como instrumento de ação educativa na saúde, bem como às tendências pedagógicas e às tecnologias educacionais $\mathrm{e}$ suas aplicações na enfermagem.

Dessa maneira, planejou-se a utilização de ferramentas da Internet na modalidade assíncrona, ou seja, onde a comunicação ocorre em tempo flexível, conforme o ritmo e a disponibilidade do aluno, por informações hipermídia na World Wide Web $(W W W)$ e correio eletrônico (e-mail).

Esta proposta, apesar de pautar-se na concepção construtivista, neste momento ainda se apresenta em uma perspectiva instrucional, visando vivenciar uma transição educacional, passando de uma formação estritamente presencial para uma situação de intercâmbio de informações on-line. Assim, objetivou-se proporcionar aos alunos condições de se comunicarem com os professores ou colegas, 
comentarem as aulas, discutirem temas relacionados à disciplina em andamento, enviarem sua produção aos professores e acessarem outras informações importantes para um bom desempenho no curso, ampliando e diversificando as formas de comunicação e possibilitando uma maior flexibilização do processo educacional.

A adoção destas novas ferramentas no ensino de didática atendeu, especialmente, três objetivos educacionais: planejar e avaliar estratégias de ensino nas atividades educacionais dos enfermeiros; exercitar a comunicação em situação de ensino aprendizagem em enfermagem; e exercitar a aprendizagem contínua interpretando suas próprias crenças, valores, percepções e atitudes diante das situações vividas.

Para tanto, disponibilizou-se, no site da Escola, uma home page, para os alunos matriculados na disciplina, desenvolvida através do aplicativo Microsoftâ FrontPage de edição e publicação de páginas da web, em HyperText Markup Language (HTML), linguagem computacional utilizada para formatação de textos a serem veiculados na internet.

A home page desta disciplina foi estruturada com tópicos os seguintes tópicos: objetivos educacionais; conteúdos programáticos; links de sites, artigos on-line, bibliotecas virtuais, portais educacionais e jornais eletrônicos; $e$ mail da disciplina; slides apresentados em sala de aula; trabalhos elaborados por grupos de alunos; e referências bibliográficas relacionadas à temática abordada.

Para o desenvolvimento desse projeto contou-se com a participação de uma aluna monitora bolsista do Departamento de Ensino para a edição dos hipertextos e links e a colaboração da Seção de Informática da Escola, responsável pelo suporte técnico de publicação da página na web. Disponibilizou-se, também, a sala de aula de informática da Escola, com 12 computadores multimídia ligados à rede, em horários programados para a elaboração dos trabalhos em grupo, e com a sala Pró-aluno de livre acesso aos alunos de Graduação com 14 computadores.

\section{OBJETIVOS}

- Caracterizar o perfil dos alunos em relação ao conhecimento de informática;

- Avaliar o site da Disciplina de Didática em Enfermagem, quanto à forma e conteúdo e sua aplicação no ensino.

\section{MÉTODO}

Trata-se de uma pesquisa quantitativa, exploratória descritiva que visou caracterizar o perfil dos discentes em relação aos conhecimentos de informática, bem como, avaliar a aplicação de ferramentas assíncronas no ensino da Disciplina Didática em Enfermagem.
A população constituiu-se de 80 alunos matriculados na Disciplina Didática em Enfermagem do primeiro semestre do ano letivo de 2003, do Curso de Graduação em Enfermagem da Escola .

O Projeto de Pesquisa foi aprovado pelo Comitê de Ética da Instituição campo de estudo e após a aprovação deste foi agendado um dia com alunos que cursaram a Disciplina de Didática no primeiro semestre de 2003.

A coleta de dados foi realizada no dia 22 de outubro de 2003, no qual foi explicada a voluntariedade em participarem do mesmo após a anuência do Termo de Responsabilidade. Os alunos demoraram em média 7 dias para a devolução do questionário, contando-se com a colaboração de 36 alunos (45\% da população).

O instrumento de coleta de dados foi um questionário composto por duas partes sendo uma referente à caracterização dos alunos com seis questões fechadas e outra sobre a avaliação do site com onze questões fechadas e duas questões dissertativas (Anexo I) .

Os dados obtidos foram registrados e tabulados sob forma de planilhas eletrônicas Excel, e apresentados em tabelas e gráficos com números absolutos e percentuais. Sendo a análise pautada nos dados de maior incidência correlacionando com o referencial teórico adotado.

\section{RESULTADOS E DISCUSSÃO}

\section{Caracterização dos alunos quanto à utilização do computador}

A maioria dos alunos $(94,4 \%)$ que participaram do estudo eram do sexo feminino, refletindo o perfil de gênero feminino predominante na Escola de Enfermagem e na profissão como um todo.

Em relação à faixa etária verificamos predominância de alunos $(94,4 \%)$ entre 19 e 25 anos. Como vemos a população é composta por adultos-jovens, sendo este resultado compatível com o encontrado por alguns autores em seus estudos ${ }^{(10-11)}$. Esta faixa etária era esperada, pois os entrevistados são estudantes de Universidades Públicas, jovens que, freqüentemente, terminam o Ensino Médio e logo se inserem na Universidade. O mesmo perfil etário não é encontrado nos estudos realizados em Universidades Particulares onde a maioria dos alunos são trabalhadores, principalmente, técnicos e auxiliares de enfermagem, pelo fato de o curso ser oferecido em tempo parcial o que possibilita aos alunos trabalharem enquanto cursam a Universidade ${ }^{(12)}$.Todos os alunos (100\%) entrevistados utilizam o computador sendo que $34(94,4 \%)$ possuem computador em casa ligado 
à Internet. Os alunos que não possuem computador em casa acessam a Internet na Escola onde estudam, casa de parentes, amigos e em casas comerciais como Lan-House.

As atividades mais realizadas pelos alunos no computador estão demonstradas na Tabela 1.

Tabela 1 - Distribuição das atividades realizadas no computador pelos alunos de graduação da Escola de Enfermagem do Município de São Paulo - São Paulo - 2003

\begin{tabular}{|c|c|c|}
\hline Atividades realizadas no computador* & $\mathbf{N}$ & $\%$ \\
\hline Digitação de trabalhos & 34 & 94,4 \\
\hline Internet & 33 & 91,3 \\
\hline Apresentação de trabalhos & 32 & 88,8 \\
\hline Pesquisa bibliográfica & 31 & 86,1 \\
\hline E-mail & 11 & 30,5 \\
\hline Aulas & 4 & 11,1 \\
\hline Entretenimento & 3 & 8,3 \\
\hline Sistema Júpiter** & 2 & 5,5 \\
\hline
\end{tabular}

*Os sujeitos da pesquisa informaram mais de uma atividade.

**O Sistema Júpiter é um sistema computacional próprio da Instituição Educacional do estudo, que possibilita aos alunos acessarem o histórico escolar e obterem informações sobre as disciplinas.

Verificou-se que os alunos utilizam o computador com maior frequiência para a realização de atividades escolares como digitação $(94,4 \%)$ e apresentação de trabalhos $(91,3 \%)$ e com menor freqüência para atividades de entretenimento $(8,3 \%)$. Fazendo uso em maior frequiência dos programas de edição de texto e de apresentação, o que se assemelha aos achados de um estudo realizado ${ }^{(10)}$.
Observou-se que o desenvolvimento da tecnologia da informação trouxe a necessidade da utilização do computador em várias atividades humanas inclusive nas escolares. Portanto, a incorporação dos novos recursos da tecnologia na educação dos profissionais tornou-se um grande desafio para a Enfermagem brasileira, sendo que estes recursos vêm sendo pouco explorados pelas Escolas de Enfermagem ${ }^{(13)}$.

Assim, defende-se a criação de Disciplina de Informática em Enfermagem visando o desenvolvimento de competências e habilidades de informática em enfermagem para compreender a aplicação dos seus recursos na prática profissional e não apenas serem instruídos em competências computacionais básicas ${ }^{(16-17)}$.

Para que haja uma compreensão da utilização dos recursos de informática na prática de enfermagem é necessário que o ensino de informática promova a interdisciplinariedade definindo uma rede de relações entre as diversas disciplinas da graduação, dessa forma, não sendo realizado em uma disciplina isolada ${ }^{(18)}$.

Portanto, a disciplina de informática em enfermagem não deve focalizar apenas o treinamento básico em informática propriamente dita (editores de texto, apresentação, chats, fóruns, etc), mas permitir que os alunos visualizem as potencialidades e limitações da utilização desses recursos em sua prática profissional.

No Gráfico 1 abaixo observa-se o grau de habilidade dos alunos em relação aos recursos da Internet.

Gráfico 1- Grau de habilidade dos alunos da Escola de Enfermagem do Município de São Paulo em relação aos recursos da Internet - São Paulo - 2003

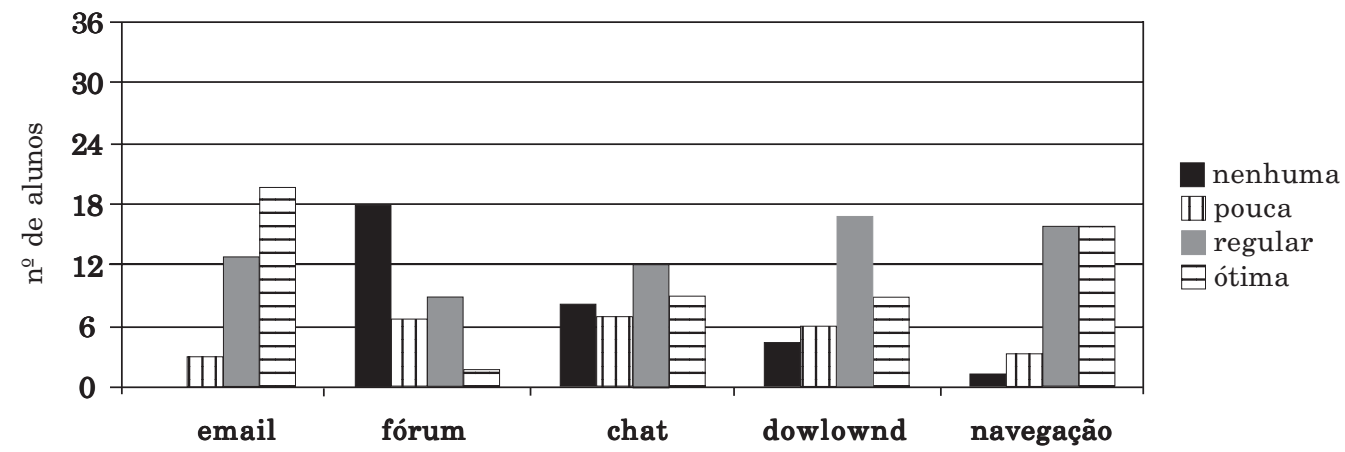

A maioria dos alunos $(55,5 \%)$ tem maior habilidade em relação ao manuseio do $e$-mail e apresentam de ótima a regular habilidade em navegação na Internet (44,4\%).

Os recursos que os alunos apresentam menor habilidade foram o download de programas e os instrumentos que permitem maior comunicação e interatividade comofóruns e chats, pois $47,2 \%$ dos alunos possuem regular habilidade em dowlowd de programas, $50 \%$ dos alunos não têm habilidade com fóruns, bem como 22,2\% e 33,3\% dos alunos possuem, respectivamente, nenhuma e regular habilidade com chats.

Associando esses dados às atividades realizadas no computador pelos alunos de graduação, conforme Tabela 1, observa-se que apesar do $e$-mail ser pouco utilizado, nas atividades escolares, os alunos apresentam uma grande habilidade em seu manuseio, bem como com relação aos recursos de navegação na Internet. 
Esses achados intensificam a necessidade da aplicabilidade da informática no ensino de graduação em enfermagem, possibilitando que os alunos sejam desafiados a refletir e experienciar o uso da informática na assistência, no ensino, na administração e na pesquisa em enfermagem, visando a construção de uma nova concepção da informática aderente à prática profissional.

A implementação desses recursos no ensino depende de uma concepção de educação que valoriza o diálogo e considera "o aluno como um sujeito que constrói seu caminho rumo ao conhecimento", sendo o professor aquele que auxilia nesta construção ${ }^{(19)}$.

\section{Avaliação do site pelos discentes}

A avaliação dos alunos sobre a forma, conteúdo e utilização do site como ambiente pode ser verificada no Gráfico 2.

Gráfico 2 - Distribuição das respostas obtidas na avaliação dos aspectos: conteúdo, forma e utilização como ambiente de aprendizagem do site pelos alunos da Escola de Enfermagem do Município de São Paulo - São Paulo - 2003

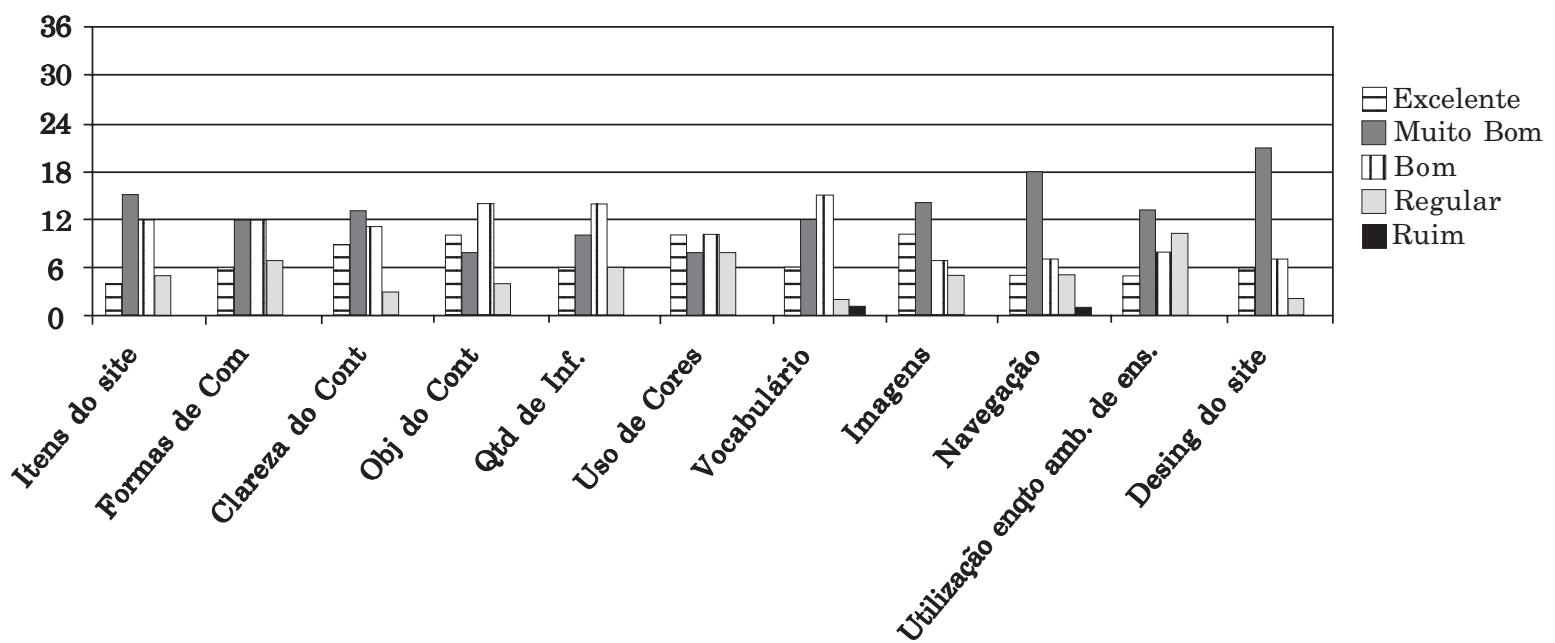

Com relação ao conteúdo do site os discentes avaliaram os seguintes tópicos: objetividade - muito bom (41,6\%); clareza - muito bom $(36,1 \%)$; quantidade de informações - bom (38,8\%); e vocabulário utilizado - bom (41,6\%).

Ainda comentaram que o recurso proporcionou facilidade de acesso às informações sobre a temática de Didática, aos artigos de revista e jornais e aos trabalhos de outros colegas, além de reduzir os custos com xerox, como pode ser exemplificado pelas falas:

... ele nos permite ter acesso às informações da matéria e ao trabalho de nossos colegas.

...o legal foi que a gente pode ter acesso a artigos de jornais e revistas além do trabalho de nossos colegas.

... foi bom porque a matéria estava na Internet e economizávamos.

Entretanto alguns discentes referiram que houve dificuldade no acesso às informações, o que depreende-se nas falas a seguir:

... é um bom recurso, mas o acesso às informações é difícil.

...o site é bacana, mas o acesso à informação fica difícil às vezes.

...utilizei pouco porque algumas vezes a conexão era difícil
Quanto à forma do site os alunos avaliaram aspectos como: itens- muito bom (41,6\%); uso de cores - excelente $(27,7 \%)$; imagens - muito bom $(38,8 \%)$; designer - muito bom $(58,3 \%)$; formas de comunicação - muito bom $(33,3 \%)$; e navegabilidade - muito bom $(50 \%)$.

Os discentes avaliaram, ainda, como muito bom $(36,1 \%)$ a utilização do site em ambiente de ensino, destacando como pontos positivos a estrutura e as formas de comunicação, por permitirem ampliar e diversificar a interação entre professores, alunos e o próprio grupo de alunos, sugerindo que este instrumento seja utilizado em outras disciplinas, considerando-o facilitador da aprendizagem, o que se depreende nas seguintes falas:

... ele é interessante, bem estruturado, organizado e completo.

... muito bom facilita o aprendizado.

... o site melhorou a comunicação da turma.

Verifica-se que os alunos apontaram o site como um recurso facilitador da aprendizagem, possibilitando ampliar o acesso à informações, melhorar o acompanhamento da Disciplina, bem como facilitar a organização das atividades e a comunicação da turma entre si e com os docentes. 
O mesmo resultado foi percebido em outros estudos ${ }^{(20-22)}$, pois os alunos acreditam ser este um instrumento importante na aquisição de conhecimentos, permitindo revisar a matéria, esclarecer dúvidas, estabelecer canais de comunicação entre os alunos e os docentes, além de reforçar e fixar os conteúdos teóricos.

Entretanto, alguns discentes avaliaram como aspecto desfavorável a interação entre os sujeitos do ensino sugerindo que deveriam ter sido mais estimulados a acessarem o site, como demonstram as falas a seguir:

...não vi tanta importância em acessá-lo. Só usava para pegar as matérias das aulas.

... deveria ter mais estímulo para nos incentivar a utilizar o recurso.

Apesar dos discentes avaliarem como muito boa a forma de comunicação $(33,3 \%)$ e a utilização do site enquanto ambiente de ensino (36,1\%), justifica-se a baixa interatividade pelo fato de ter sido utilizado, apenas, o e-mail como recurso de comunicação, mostrando a necessidade de intensificar o uso de ferramentas como fóruns e chats.

Conforme observa-se no Gráfico1 os alunos possuem pouca habilidade com fóruns e chats e é preciso que estas habilidades sejam desenvolvidas para que os discentes possam identificar quais as potencialidades e limitações destes recursos em sua prática profissional.

Dessa forma, é de grande importância que as escolas de enfermagem se envolvam neste contexto para que desde a formação os enfermeiros utilizem as novas tecnologias e reflitam sobre suas possibilidades e limites.

Portanto, o ensino mediado pelo computador requer processos contínuos de avaliação e de mudança da concepção educacional dos discentes e docentes, gerando re-significações de valores e de atitudes a partir do concreto vivido.

\section{REFERÊNCIAS}

1. Brasil. Lei n. 9394, de 1996. Dispões sobre as Diretrizes e Bases da Educação Nacional [legislação na Internet]. Brasília; 1996. [citado 2003 jul. 15]. Disponível em: hhttp//prolei.cibecec.inesp.gov.br

2. Chaves E. Tecnologia e educação: o futuro da escola na era da informação. São Paulo: Mindware; 1999.

3. Libâneo JC. Didática. São Paulo: Cortez; 1997.

4.Maselto M. Didática: aula como o centro. São Paulo: FTD; 1994.

5. Lévy P. As tecnologias da inteligência: o futuro do pensamento na era da informática. Rio de Janeiro: Editora 34; 1999.

\section{CONCLUSÃO}

Este estudo teve a finalidade de descrever a opinião dos discentes sobre a forma e o conteúdo do site e a aplicação deste como recurso instrucional no ensino da Disciplina de Didática em Enfermagem, bem como, caracterizar os alunos em relação aos conhecimentos de informática.

Participaram da pesquisa 36 alunos, sendo que a maioria era do sexo feminino $(94,4 \%)$ e estavam na faixa etária de 19-25 anos $(94,4 \%)$. Todos os entrevistados faziam uso do computador e 34 $(94,4 \%)$ possuíam computador em casa ligado à Internet.

Observou-se que estes faziam uso em maior freqüência de programas de digitação $(94,4 \%)$ e apresentação $(91,3 \%)$, fazendo menor uso do computador para entretenimento $(8,3 \%)$.

Apresentaram maior habilidade relacionada ao manuseio do $e$-mail $(44,4 \%)$ e a navegação de sites $(47,2 \%)$ e menor habilidade com o download de programas $(55,5 \%)$, fóruns $(50 \%)$ e chats $(33,3 \%)$.

Os discentes avaliaram a forma, o conteúdo e a utilização do site como ambiente de ensino de bom a muito bom, pelo fato de ampliar e diversificar as formas de comunicação entre discentes e docentes, permitir a aquisição de novos conteúdos, além de facilitar o aprendizado.

Destacaram como pontos favoráveis a maior possibilidade de obter informações além da sala de aula, bem como, a maior comunicação dos alunos entre si e destes com os professores, sugerindo a utilização deste recurso em outras disciplinas.

Verificou-se também que alguns alunos referiram a pouca interatividade professor-aluno, o que deve ser revisado a partir da implementação de ferramentas que permitem maior comunicação como fóruns e chats.

Frente ao exposto conclui-se que o ensino mediado pelo computador na enfermagem é um desafio a ser conquistado, exigindo mudanças na postura de discentes e docentes frente ao processo educacional.

6. Peres HHC, Kurcgant P. O ser docente de enfermagem frente à informática. Rev Lat Am Enferm [periódico na Internet]. 2004 [citado 2004 jul. 20];12(1):[cerca de 8 p.]. Disponível em: http:/ /www.scielo.br/pdf/rlae/v12n1/v12n1a14.pdf

7. Tiramonti G. Los imperativos de las políticas educativas de los 90. Rev Fac Educ [periódico na Internet].1997[citado 2004 jul. 20];23(1/2):[cerca de 7 p.]. Disponível em: http://www.scielo.br/ scielo.php?script=sci_arttext \&pid=S0102-25551997000100 005\&lng=pt\&nrm=iso\&tlng=es 
8. Bastos MAR, Guimarães EMP. Educação á distância na área de enfermagem: relato de uma experiência. Rev Lat Am Enferm. 2003;11(5):685-91.

9. Christiane L, Ramos MP, Bessa R, Sigulem D. O papel do ensino à distância na educação médica continuada: uma análise crítica. Rev Assoc Med Bras [periódico na Internet]. 2003 [citado 2004 jul. 20];49(3):[cerca de 5 p.]. Disponível em: http:// www.scielo.br/scielo.php?script=sci_arttext\&pid=S0104$42302003000300039 \& \operatorname{lng}=$ pt\&nrm=iso

10. Peres HHC, Duarte YAO, Maeda ST, Colvero LA. Estudo exploratório sobre a utilização dos recursos de informática por alunos de graduação em enfermagem. Rev Esc Enferm USP. 2001;35(1):88-94.

11. Santos SR. Análise das atitudes de enfermeiros e estudantes de enfermagem na Paraíba-BR quanto à utilização do computador. Rev Lat Am Enferm. 2001;6(9):56-61.

12. Botta LMMG. O estudo da introdução à informática em enfermagem: proposta de conteúdos e estratégias [tese]. São Paulo: Universidade Federal de São Paulo; 1999.

13. Marques IR, Marin HF. Enfermagem na WEB: O processo de criação e validação de um WEB site sobre doença arterial coronariana. Rev Lat Am Enferm [periódico na Internet]. 2002[citado 2004 jul. 20];10(3):[cerca de 10 p.]. Disponível em: http:/ /www.scielo.br/scielo.php?script=sci_arttext\&pid=S0104$11692002000300005 \& \operatorname{lng}=\mathrm{pt} \& \mathrm{nrm}=$ iso

14. Nagelkerk J, Ritola PM, Vandort PJ. Nursing informatics: the trend of the future. J Contin Educ Nurs. 1998;29(1):17-21.
15. Saranto K, Leino-Kilpi H. Computer literacy in nursing: developing the information technology syllabus in nursing education. J Adv Nurs. 1997;25(2):377-85.

16. Marin HF. Nursing informatics in Brazil: a brazilian experience. Comput Nurs. 1998;16(6): 327-32.

17. American Nurses Association (ANA). The scope of practice for nursing informatics. Washington: American Nurse Publishing; 1994. p. 1-15.

18. Luis MA, Moala FA, Évora YDM, Scochi CGS, Rodrigues RAPR. Avaliação de uma disciplina de informática por graduandos de enfermagem. Rev Lat Am Enferm. 1995; 3(2):59-69.

19. Lopes MVO, Araújo TL, Neto HB. A informática e as correntes pedagógicas na informática, Rev RENE. 2001;2(2):52-68.

20. Santos BRL, Funcke LB, Ribeiro NRR, Uebel WS. Percepção dos alunos de graduação sobre a informática no ensino de enfermagem. Rev Gaúcha Enferm. 1993;14(1):40-4.

21. Zem-Mascarenhas SH, Cassiani SHB. Desenvolvimento de um software educacional para o ensino de enfermagem pediátrica. Rev Lat Am Enferm. 2001;6(9):13-8.

22. Maio M, Ferreira MC. Experience with the first Internet-based course at the Faculty of Medicine, University of São Paulo. Rev Hosp Clin Fac Med Univ São Paulo. 2001;56(3):69-74. 


\section{ANEXO I - Questionário de Avaliação}

Prezado Aluno:

O preenchimento deste questionário é importante para que se possa realizar a avaliação do site da disciplina de didática em enfermagem. Assim, desde já agradeço sua contribuição e o tempo despendido neste processo. A preservação de sua identidade é assegurada.

A) Caracterização dos sujeitos

1. Idade:

2. Sexo: $\mathrm{F}(\mathrm{)} \quad \mathrm{M}(\mathrm{)}$

3. Qual o semestre do curso de graduação de enfermagem que você está cursando?

4. Você utiliza o computador nas atividades da EEUSP: S( ) N( )

Se sim;

Quais atividades?

5. Você tem computador em casa? S ( ) N( )

Se sim:Está ligada a Internet? $\quad \mathrm{S}(\mathrm{r}) \quad \mathrm{N}($ )

6. Se não: Você tem outro tipo de acesso ao computador e a Internet fora da EE? S ( ) N ( )

Se sim: Onde?

7. Avalie sua habilidade com relação aos recursos abaixo:

a) E-mail: $\quad$ nenhuma ( ) pouca ( ) razoável ( ) ótima ( )

b) Fórum: nenhuma ( ) pouca ( ) razoável ( ) ótima ( )

c) Chat: nenhuma ( ) pouca ( ) razoável( ) ótima ( )

d) Download: nenhuma ( ) pouca ( ) razoável ( ) ótima ( )

e) Navegação: $\quad$ nenhuma ( ) pouca ( ) razoável ( ) ótima ( )

B) Avaliação do site

\begin{tabular}{|l|l|l|l|l|l|}
\hline \multicolumn{1}{|c|}{ ITENS } & EXCELENTE & MUITO BOM & BOM & REGULAR & RUIM \\
\hline 1. Itens do site & & & & & \\
\hline $\begin{array}{l}\text { 2. Formas de } \\
\text { comunicação }\end{array}$ & & & & & \\
\hline $\begin{array}{l}\text { 3. Clareza do } \\
\text { conteúdo }\end{array}$ & & & & & \\
\hline $\begin{array}{l}\text { 4. Objetividade } \\
\text { do conteúdo }\end{array}$ & & & & & \\
\hline $\begin{array}{l}\text { 5. Quantidade } \\
\text { de Informação }\end{array}$ & & & & & \\
\hline $\begin{array}{l}\text { 6. Uso de cores } \\
\text { 7. Vocabulário } \\
\text { utilizados }\end{array}$ & & & & & \\
\hline $\begin{array}{l}\text { 8. Imagens } \\
\text { foto/vídeo) }\end{array}$ & & & & & \\
\hline 9. Navegação & & & & & \\
\hline $\begin{array}{l}\text { 10. Utilização } \\
\text { enquanto } \\
\text { ambiente de } \\
\text { ensino }\end{array}$ & & & & & \\
\hline $\begin{array}{l}\text { 11. Desing do } \\
\text { site }\end{array}$ & & & & & \\
\hline 12. Dê sua opinião sobre a utilização do site na disciplina de didática em enfermagem. \\
\hline 13. Fale sobre as facilidades e dificuldades que você encontrou no uso do site na disciplina. \\
\hline
\end{tabular}

